\title{
Development and Performance Evaluation of a Livestock Feed Chopper/Pulverizer
}

\author{
*ISHOLA, TA; HASSAN, SB \\ Department of Agricultural and Biosystem Engineering, University of Ilorin, Ilorin, Kwara State, Nigeria \\ *Corresponding Author Email: istab@unilorin.edu.ng
}

\begin{abstract}
Crop residues are bulky and low in nutrients. Their size reduction is imperative in order to compound them with other feed ingredients to achieve balanced feedstock for livestock. A chopping and pulverizing machine was designed and constructed to chop and pulverized feed materials. It comprises of chopping hopper, pulverizing hopper, metering device, chopping/ pulverizing chamber, screen and the processed feed outlet. The performance of the machine was evaluated on the basis of throughput capacity, pulverizing efficiency, scatter losses as dependent variables while moisture content was the independent variable. There were two level of speeds (1500 rpm and $2100 \mathrm{rpm}$ ) and five levels of moisture content (13\%, 16\%, 19\%, $21 \%, 24 \%$, and $27 \%$ dry basis). The throughput capacity, pulverizing efficiency had highest values of $222 \mathrm{~kg} / \mathrm{h}$ and of $92.5 \%$ respectively at moisture content level of $13 \%(\mathrm{db})$ and $2100 \mathrm{rpm}$ speed. However, the least scatter losses obtained was $2.5 \%$ at moisture content level of $27 \%(\mathrm{db})$ and $1500 \mathrm{rpm}$ speed. As the moisture content increased, throughput capacity, pulverizing efficiency and scatter losses decreases at both speeds. The developed machine could enhance the use of crop residues in feeding livestock which could ultimately reduce the cost of livestock feed production.
\end{abstract}

\section{DOI:https://dx.doi.org/10.4314/jasem.v25i9.14}

Copyright: Copyright (C) 2021 Ishola and Hassan. This is an open access article distributed under the Creative Commons Attribution License (CCL), which permits unrestricted use, distribution, and reproduction in any medium, provided the original work is properly cited.

Dates: Received: 09 May 2021; Revised: 12 August 2021; Accepted: 12 September 2021

Keywords: Chopping, Pulverization, Livestock, Throughput capacity

Livestock farmers in the tropics often have to contend with the problems of getting balanced diet for their animals during the dry season when crop residues are low in quantity and quality (Kellems and Church, 1998). Satisfying the nutritional needs of animals during the dry season is a serious issue as inadequate feeding of livestock limits their productivity in terms of growth and milk yield which ultimately diminishes profit of the farmer. Underfed animals also are not agile and prone to disease and reduction in fertility. In urban areas, natural grassland scarce and farmer depend on grown pastures, crop residues, agro industrial by-product to feed their animals. Silva et al. (2008) reported that due to the seasonal availability of crop residues and fodders in urban areas, the scarcity of agro industrial by-product and the high prices of formulated feeds would make it difficult to fulfil the dietary needs of the expanding animal population. To tackle the limiting supply of livestock feed, farmers rely on crop residues for their feed supply. Stovers are dry stalks from mature maize or guinea corn, without grains. Cereal stovers are popular for feeding livestock. In the semi-arid areas guinea corn and maize stovers are vital part of ruminant animal feeds during the dry season which help to sustain feed supply and survival (Sibanda, 1986). However, cereal stovers are bulky, fibrous and relatively poor in nutritive value. Likewise, low ease of digestion and bulkiness of stovers, the poor crude protein quality and the lack of other vital nutrients limit its use in the diets of productive animals (Dzowela, 1987). Dzowela (1987) asserted that crop residues could be augumented with brans and millings, oilseed cakes, legumes and fodder from multipurpose trees. Experimental results with sheeps reported by Osafo et al. (1993) where chopped sorghum stover combined with mineral lick was sufficient to sustain the weight of rams between the age 15 and 20 months. It was claimed that chopped sorghum stover with generous amount of minerals and no other supplement was a sustainable dietary strategy for maintaining weight in sheep are close to maturity. Crop residue could be managed by employing processing technologies for the production of balanced straw-based feed for animals (Walli et al., 2012). Physical treatment includes chopping, shredding, grinding and pelletization. Abayineh (2019) adapted two hammer mills for crushing crop residues in order to make livestock feeds. The crushing efficiency obtained ranged from 94 to $99.33 \%$ while the throughput capacity ranged from 78.68 to $152.54 \mathrm{~kg} / \mathrm{h}$. There were indications that size reduction and pelletization of fibrous materials increased the exposed surface area which accelerate the digestibility in the intestines of livestock. Also, size reduction and pelletization results in more than $30 \%$ increase in feed intake (Hoque et al., 2007). Lyu et al. (2020) asserted 
that size reduction of feed ingredients further enhances the ability of livestock to digest the nutrients in the feeds. The bulkiness and low nutrients content of the crop residues necessitate size reduction in order to be compounded with other feed ingredients to achieve balanced feedstock for livestock. Therefore, the aim of this study was to design, fabricate and investigate the performance of a combined feed chopping and pulverizing machine for processing crop residue for ease of pellet formation from them.

\section{MATERIALS AND METHODS}

Description of the feed chopper/pulverizer: The livestock feed chopper/pulverizer was designed and fabricated (figure 1). It comprises of chopping hopper, pulverizing hopper, metering device, chopping/ pulverizing chamber, screen and the processed feed outlet. The two hoppers were trapezoidal in shape. They were raised $30^{\circ}$ above the horizontal plane to aid the free flow of feed materials (stovers and grasses) in the machine. The chopping/pulverizing chamber comprised of a chopping section which has sharp edged rectangular steel blades for cutting fed materials into desired length (sizes) and a pulverizer which has swinging steel hammers mounted on a rotating shaft. The hammers continuously beat and breakdown the materials in the pulverizer until they are small enough go through the apertures of the screen. The screen is a detachable curved metal screens for passage of pulverised materials. The processed feed outlet was the point of collection of the pulverized materials. The chopping section had no screen below it.

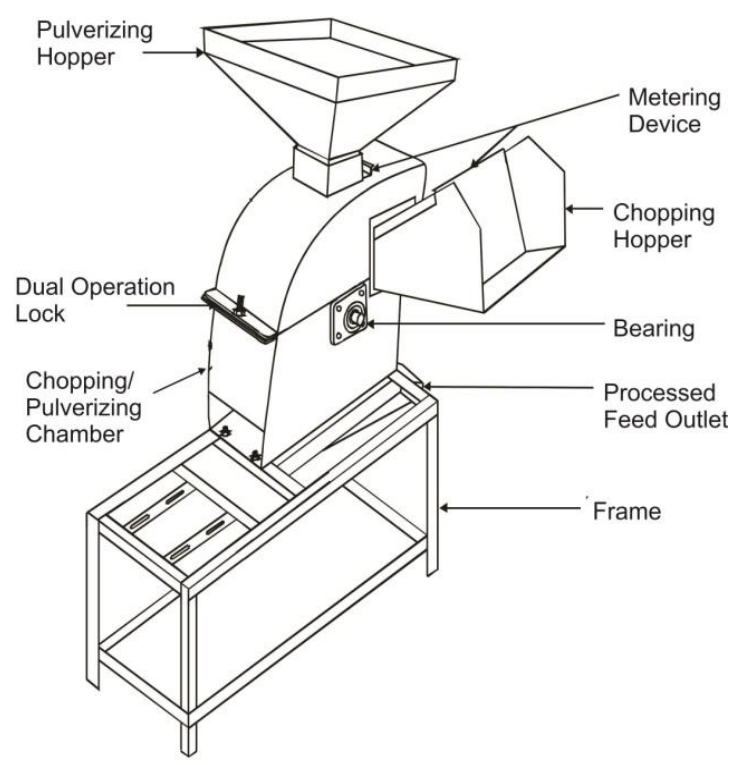

Fig 1. Isometric View of the Livestock Feed Chopper/Pulverizer

Design of the components of the machine: In designing the machine, availability and strength of the selected fabrication materials to withstand the various loads from the operation of the machine were duly considered. The angle of repose of the feed materials were also considered in the configuration of the hoppers. Likewise, arrangement of the chopping knifes, pulverizing hammers and aperture of screen to give desired material sizes were considered. In order to design the hammers inside the pulverizing chamber, equation (1) given by Khurmi and Gupta (2005) was used

$$
\frac{M_{b}}{I}=\frac{\sigma_{b}}{y}
$$

Where $\mathrm{M}_{\mathrm{b}}$ is Maximum bending moment of the rectangular hammer $(\mathrm{Nm})$; I is moment of inertia $\left(\mathrm{m}^{4}\right)$; $\sigma_{\mathrm{b}}$ is Allowable stress on the steel hammer $250 \mathrm{MPa}$ (Khurmi and Gupta, 2005); y is distance of the outermost layer of the bar from the neutral axis (m). The dimensions of the hammer were designed to length of $0.06 \mathrm{~m}$, width of $0.008 \mathrm{~m}$ and thickness of $0.004 \mathrm{~m}$.

The cutting force of the rotary knives determined by applying equation (2) as given by Ebunilo et al. (2010)

$$
F_{C}=\frac{M_{T} \omega^{2} \mathrm{D}_{\mathrm{K}}}{2}
$$

Where $\mathrm{F}_{\mathrm{C}}$ is cutting force $(\mathrm{N}) ; \mathrm{M}_{\mathrm{T}}$ is total mass of the two knives $(\mathrm{kg})$; $\mathrm{D}_{\mathrm{K}}$ is length of the knife $(\mathrm{m})$; $\omega$ is angular velocity of knife ( $\mathrm{rad} / \mathrm{s})$. The cutting force of the knife was calculated to be $129 \mathrm{~N}$

The nominal belt pitch length was computed with the formula given by Khurmi and Gupta (2005):

$$
L=2 \mathrm{C}+\frac{\pi}{2}\left(\mathrm{D}_{1}+\mathrm{D}_{2}\right)+\left[\frac{\left(\mathrm{D}_{2}-\mathrm{D}_{1}\right)^{2}}{4 \mathrm{C}}\right]
$$

Where $D_{1}$ is of motor pulley diameter; $D_{2}$ is of chopper/pulverizer shaft pulley diameter; $\mathrm{C}$ is center to center distance between electric motor and chopper/pulverizer pulley. From the design, standard A50 was chosen.

According to Khurmi and Gupta (2005), for a solid shaft which has little or no axial load, the shaft diameter was calculated by:

$$
d^{3}=\frac{16}{\pi S_{s}} \times \sqrt{\left(K_{b} M_{b}\right)^{2}+\left(K_{t} M_{t}\right)^{2}}
$$

Where $d$ is the shaft Diameter (m); $S_{S}$ is Allowable stress $\left(40 \times 10^{6} \mathrm{Nm}^{-2}\right)$ (Hall et al., 1980); $K_{b}$ is Combine shock and fatigue factor applied to bending 
moment (1.0) (Hall et al., 1980); $M_{b}$ is bending moment $(\mathrm{Nm}) ; K_{t}$ is Combine shock and fatigue factor applied to torsional moment $(1.0) ; M_{t}$ is Torsional moment $(\mathrm{Nm})$. The computed diameter of the shaft was $38 \mathrm{~mm}$. The detailed dimensions of the machine are as shown in figure 2 .

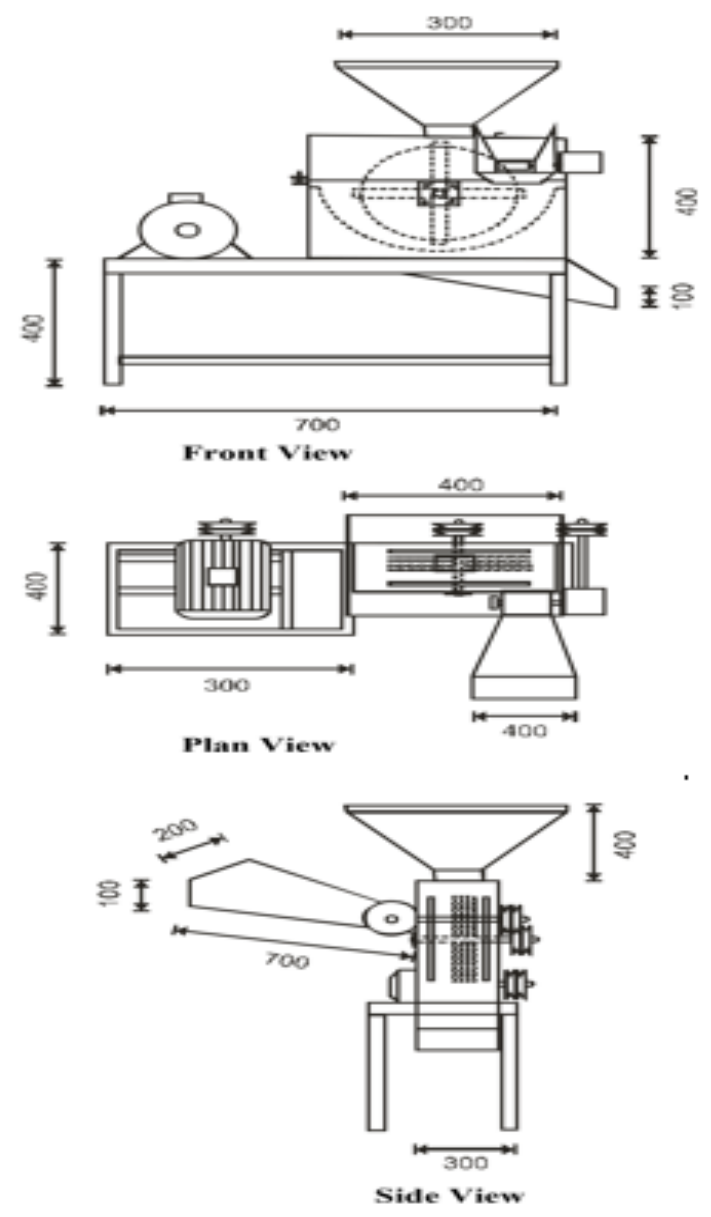

Note: All dimension in mm

Fig 2. The Orthographic view of the machine

Principle of operation of the machine: The fabricated machine (figure 3) was operated by collecting crop residues like stover and feeding them into the chopping section of the machine. As the materials entered through the hopper, the high-speed rotating knives cut the materials into predetermined lengths of chop and were immediately collected below the machine. The chopped materials were further dried to attain low moisture contents which would enhance the pulverisation process. The dried chopped materials were fed into the pulverizing chamber through the pulverizing hopper. The high-speed rotating hammers pulverized the by impacting blows on materials inside the chamber. The materials were beaten until it could pass through the apertures of the screen. At this point other materials like wheat bran, cassava peels and groundnut cake needed to be added to the livestock feed are introduced for pulverization. Materials were continuously beaten by the rotating hammers until the materials could pass through the screen perforations. The processed feed outlet is an inclined trapezoidal shaped trough made from mild steel sheets placed directly below the perforated screen of the chopping/pulverizer chamber to collect the pulverised feeds that passed through the screen section.

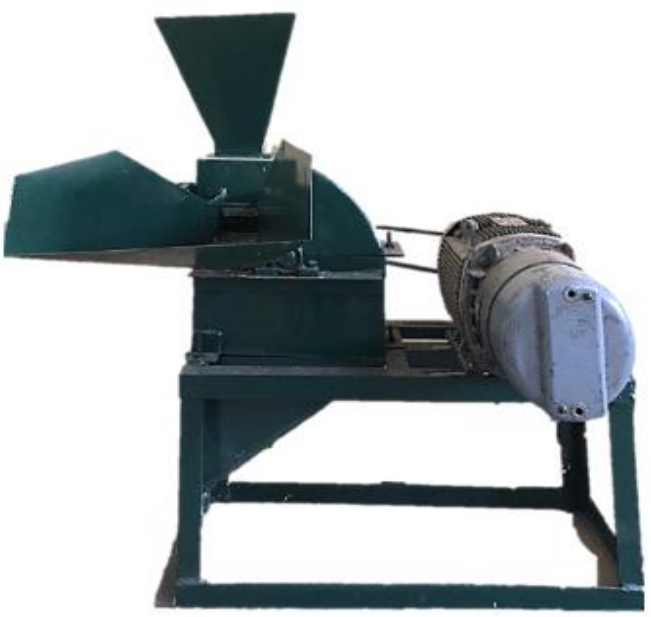

Fig 3. The Pictorial view of the fabricated machine

Procedure for the performance evaluation of the machine: Two feed stocks (elephant grass and corn stover) were obtained. They were chopped using the chopping section of the machine to an average uniform length of $20 \mathrm{~mm}$ and were sun-dried until moisture content value was $13 \%$ dry basis (db). $500 \mathrm{~g}$ of elephant grass and $500 \mathrm{~g}$ of corn stover were thoroughly mixed to form samples of $1000 \mathrm{~g}$. The machine was tested at two level of speeds $(1500 \mathrm{rpm}$ and $2100 \mathrm{rpm}$ ) and five levels of moisture content (13 $\%, 16 \%, 19 \%, 21 \%, 24 \%$, and $27 \%$ dry basis). Different pulley sizes were used to achieve the two speeds. In order to achieve the levels of moisture content, samples of $1000 \mathrm{~g}$ were conditioned by addition of calculated amount of water to increase the moisture content to the various levels. Equation (5) given by Adejumo and Abayomi (2012) was used to determine the amount of water to be added to achieve the various moisture levels. After the addition of the right quantity of water each sample was sealed in nylon bags and left for three hours for the purpose of even moisture distribution and stability (Sharma et al., 2013).

$$
Q=W_{i} \frac{\left(M_{f}-M_{i}\right)}{\left(100-M_{f}\right)}
$$

Where $\mathrm{Q}$ is the quantity of water $(\mathrm{g})$; $\mathrm{W}_{\mathrm{i}}$ is initial mass of sample $(\mathrm{g}) ; \mathrm{M}_{\mathrm{f}}$ is the final moisture content $(\% \mathrm{db})$; $\mathrm{Mi}$ is initial moisture content of sample $(\% \mathrm{db})$. 
The initial moisture content of feedstock was found to be $13 \%(\mathrm{db})$. The machine was tested by the application of completely randomized design. The conditioned samples were used for the performance evaluation. Test at each moisture level was replicated three times. The screen size used was $3 \mathrm{~mm}$. Measurements were carried out for each run of the experiment. The performance indices used to evaluate the machine were throughput capacity, pulverizing efficiency and scatter losses

Determination of throughput capacity of machine: This is the ratio of the weight of feed materials reduced (pulverized) to the total time taken to complete the size reduction operation expressed in $\mathrm{kg} / \mathrm{h}$ and given as:

$$
C=\frac{W}{t}
$$

Where $\mathrm{C}$ is Throughput capacity of the machine $(\mathrm{kg} / \mathrm{h}) ; \mathrm{W}$ is Weight of the reduced feed material $(\mathrm{kg})$; $\mathrm{t}$ is Total time taken to carry out the size reduction operation $(\mathrm{h})$

Determination of pulverizing efficiency of the machine: This is the ratio of the quantity of feed materials reduced to the total quantity of feed materials fed into the hopper expressed as a percentage.

$$
P_{e}=\frac{Q_{g}}{Q_{t}} \quad x 100
$$

Where $\mathrm{P}_{\mathrm{e}}$ is the Pulverizing efficiency (\%); $\mathrm{Q}_{\mathrm{g}}$ is quantity of feed materials reduced $(\mathrm{kg}) ; \mathrm{Q}_{\mathrm{t}}$ is total quantity of feed materials fed into the hopper $(\mathrm{kg})$

Determination of scatter losses of the machine: During the size reduction operation, some reduced materials could be lost to scattering. Amount of such reduced materials were determined using the formula below and expressed as a percentage;

$$
S_{L}=\frac{Q_{L}}{Q_{t}} \times 100
$$

Where $\mathrm{S}_{\mathrm{L}}$ is the scatter losses (\%); $\mathrm{Q}_{\mathrm{L}}$ is Quantity of feed materials scattered around the machine after size reduction $(\mathrm{kg}) ; \mathrm{Q}_{\mathrm{t}}$ is Total quantity of feed material in sample $(\mathrm{kg})$

\section{RESULTS AND DISCUSSION}

Performance of the machine: The relationship between the dependent variables which were throughput capacity, pulverizing efficiency, scatter losses and independent variable which was moisture content was used investigate the performance of the machine. A fixed screen size of $3 \mathrm{~mm}$ and machine speeds of $1500 \mathrm{rpm}$ and $2100 \mathrm{rpm}$ were used throughout the investigation.

Effect of Moisture Contents on Throughput capacity: Figure 4 shows the effect of moisture content on throughput capacity of the machine at operating speeds of $1500 \mathrm{rpm}$ and $2100 \mathrm{rpm}$. The moisture content was significant at $5 \%$ level. The figure also shows that the maximum throughput capacity at moisture content value of $13 \%(\mathrm{db})$ were $204 \mathrm{~kg} / \mathrm{h}$ and $222 \mathrm{~kg} / \mathrm{h}$ at $1500 \mathrm{rpm}$ and $2100 \mathrm{rpm}$ operating speed respectively. The minimum throughput capacity at moisture content value of $27 \%(\mathrm{db})$ at were $166 \mathrm{~kg} / \mathrm{h}$ and $176 \mathrm{~kg} / \mathrm{h}$ at $1500 \mathrm{rpm}$ and $2100 \mathrm{rpm}$ operating speed respectively. It was observed that the throughput capacity decreased as the moisture content increased at both speeds. This could be due to the fact that at low moisture content it was easier to pulverize the feed material because of being crispy in nature thereby leading to high throughput capacity. This result follows the same trend reported by Abayineh (2019) where it was claimed that as the moisture content of maize stalk increased the throughput capacity of the machine decreased.

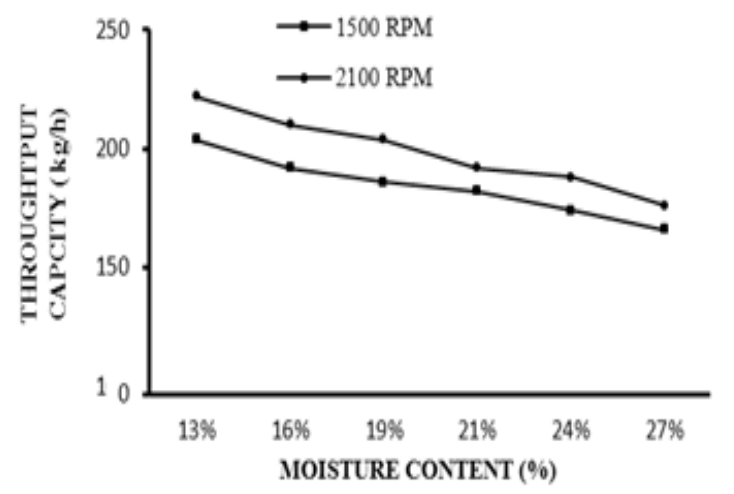

Fig 4. Effect of moisture content on the throughput capacity at two speeds

Effect of Moisture Contents on Pulverizing efficiency: Figure 5 shows the effect of moisture content on the pulverizing efficiency of the machine at operating speeds of $1500 \mathrm{rpm}$ and $2100 \mathrm{rpm}$. The moisture content was significant at $5 \%$ level. The figure also depicts that the maximum pulverizing efficiency at moisture content level of $13 \%(\mathrm{db})$ were $85.5 \%$ and $92.5 \%$ at $1500 \mathrm{rpm}$ and $2100 \mathrm{rpm}$ operating speed respectively. The minimum pulverizing efficiency at moisture content level of $27 \%(\mathrm{db})$ were $67.5 \%$ and $72.5 \%$ at $1500 \mathrm{rpm}$ and $2100 \mathrm{rpm}$ operating speed respectively. It was observed that the pulverizing efficiency decreased as the moisture content increased 
at both speeds. This could be due to the fact that at high moisture, the feedstock could be elastic thereby making it difficult to be reduced by the hammers. This result is in similar trend with that of Idris et al. (2018) where it was claimed that as the moisture content of paddy rice increased the pulverizing efficiency of the crop thresher reduced.

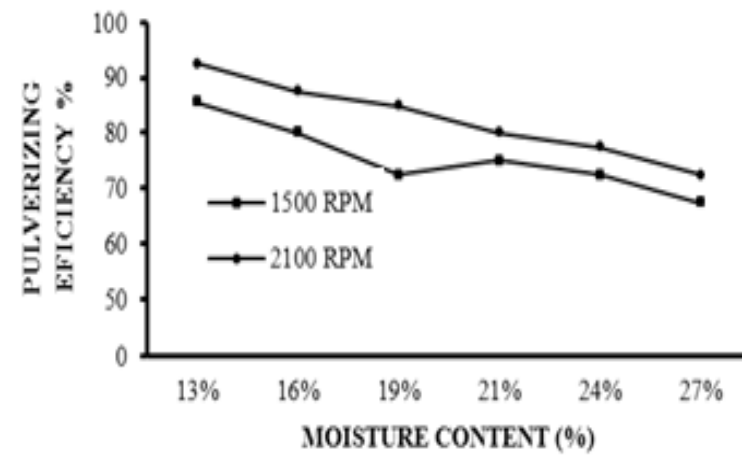

Fig 5. Effect of moisture content on the pulverizing efficiency at two speeds

Effect of Moisture Contents on Scatter Losses: Figure 6 shows the effect of moisture content on the scatter losses of the machine for the operating speeds of 1500 $\mathrm{rpm}$ and $2100 \mathrm{rpm}$. Moisture content was observed to be significant at $5 \%$ level. Also, the figure shows that the maximum percentage scatter loss at moisture content value of $13 \%(\mathrm{db})$ were $10 \%$ and $7.5 \%$ at $1500 \mathrm{rpm}$ and $2100 \mathrm{rpm}$ operating speed respectively.

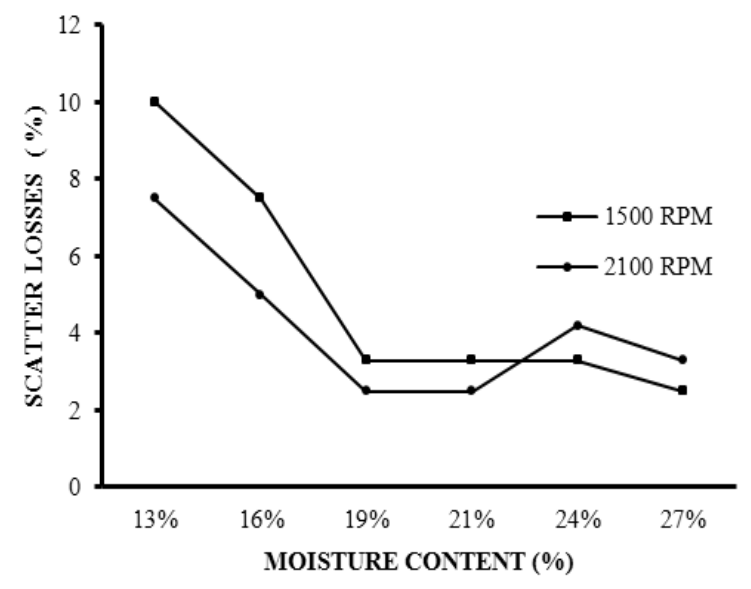

Fig 6. Effect of moisture content on the scatter losses at two speeds

The minimum percentage scatter loss at moisture content value of $27 \%(\mathrm{db})$ were $2.5 \%$ and $3.3 \%$ at $1500 \mathrm{rpm}$ and $2100 \mathrm{rpm}$ operating speed respectively. The graph depicts that the percentage scatter losses decreased as the moisture content increased at both speeds. This may be due to the fact that at low moisture content of the feedstock, the air from the hammers blows off the pulverized feedstock resulting to increase in scatter losses. Baryeh (2002) and Ojediran et al. (2010) reported that the dimensions of millet seed grain increased with the increase in their moisture content thereby becoming more difficult to be blown off. Probst et al. (2001) reported that the loss of smaller particles of ground corncobs decreased as moisture content increases due to particle cohesion.

Conclusion: A livestock feed chopper/pulverizer was designed and fabricated for livestock feeds. The performance of the machine was determined in terms of throughput capacity, pulverizing efficiency and scatter losses as dependent variables while moisture content was the independent variable. The highest throughput capacity of $222 \mathrm{~kg} / \mathrm{h}$ and pulverizing efficiency of $92.5 \%$ were obtained while the least scatter losses obtained was $2.5 \%$. The developed machine could enhance the use of crop residues which hitherto were wasted.

\section{REFERENCES}

Abayineh, A (2019). Comparative performance evaluation of top hammer miller machine to crop residue for livestock feed purpose. Chem. \& Proc. Eng. Res. (61): 7 - 13 .

Adejumo, BA; Abayomi, DA (2012) Effect of moisture content on some physical properties of moringa oleifera seed. J. Agric. \& Vet.Sci. (1)5: $12-21$.

Baryeh, EA (2002). Physical properties of millet. J. Food Eng. 51(1): 39 - 46.

Dzowela, BH (1987). Efforts to enhance maize stover utilisation for smallholder livestock producers in Malawi. Proceedings of a workshop on African Research Network for Agricultural Byproducts/International Livestock Centre for Africa. : 27-36.

Ebunilo, PO; Obanor, AI; Ariavie, GO (2010). Design and Preliminary Testing of a Hammer Mill with End-Suction Lift Capability Suitable for Commercial Processing of Grains and Solid Minerals in Nigeria. Int. J. Eng. \& Tech. (2)6:1581 - 1593 .

Hall, AS; Hollwen, KOA; Laughum, H (1980). Schaum's outline of theory and Problem of machine design. Metric selection. McGrac-Hill Books Company. New York, USA. : 67 - 70

Hoque, M; Sokhansanj, S; Naimi, L; Bi, X; Lim, J (2007). Review and Analysis of Performance and 
Productivity of Size Reduction Equipment for Fibrous Materials. ASABE paper no: 076164 St Joseph, Mich. 1 - 18 .

John, B (2005) Basic Engineering Mathematics. $4^{\text {th }}$ edition. Linacre Publishing House, Jordan Hill. Great Britain. Pp 97 - 108

Kellems, RO; Church, DC (1998) Livestock Feeds and Feeding ( $4^{\text {th }}$ edition). Prentice-Hall Inc., New Jersey, USA, pp.537 - 542.

Khurmi, RS; Gupta, JK (2005). Machine Design, $14^{\text {th }}$ Edition. S. Chand and Company Ltd. Ram Nagar, New Delhi. Pp 434-960.

Liang, L; Guo, Y (2011). Relationship between Stalk Shear Strength and Morphological Traits of Stalk Crops. International Conference on Agricultural and Biosystems Engineering. Adv. Biomed. Eng. 1(2): 288 - 290

Liu, JX; Orskov, ER; Chen, XB (1999). Optimization of steam treatment as a method for upgrading rice straw as feed. Anim. Feed Sci. \& Tech. 76(3): 345 $-357$

Lyu, F; Thomas, M; Hendriks, WH; Van der Poel, AFB (2020). Size reduction in feed technology and methods for determining, expressing and predicting particle size: A review. Anim. Feed Sci. \& Tech. (261): 1 -20.

Ojediran, JO; Adamu, MA; Jim-George, DL (2010). Some physical properties of pearl millet seed as a function of moisture content. Afr. J. Gen. Agric. 6(1): 39-46.
Idris, IS; Usman, M; Nura, AS; Ibrahim, D (2018). Modification and performance evaluation of IAR multi crop thresher for sorghum threshing. Bayero J. Eng. Tech. 13(1): 98 - 108

Osafo, ELK; Owen, E; Said, AN; Gill, EM; Mc Allan, AB (1993). Feeding sorghum stover to Ethiopian sheep and cattle: Effect of chopping and amount offered on intake and selection. A Repository of Agricultural Research Outputs. 204-206

Probst, KV; Kingsly, RP; Pinto, RI; Bali, R; Krishnakumar, P; Ileleji, KE (2013). The Effect of Moisture Content on the Grinding Performance of Corn and Corncobs by Hammer milling. Am. Soc. Agric. Biol. Eng. 56(3): 1025-1033.

Sharma, V; Pradhan, RC; Naik, SN; Bhatnagar, N; Singh, S (2013). Evaluation of a centrifugal impaction-type decorticator for shelling tung fruits. Ind. Crops and Prod. (43): $126-131$

Sibanda, S (1986). The use of crop residues in livestock production systems in the communal areas of Zimbabwe. Proceedings of a workshop on towards optimal feeding of agricultural byproducts to livestock in Africa: 140-144.

Silva, LLP; Cassoli, LD; Junior, LCR; Rodrigues, ACO; Machado, PF (2008). In situ degradability of corn stover and elephant grass harvested at four stages of maturity. Sci. Agric. (Piracicaba, Braz.) 65 (6): $595-603$.

Walli, TK; Garg, MR; Makka, HPS (2012). Crop Residue Based Densified Total Mixed Ration. Food and Agricultural Organization Animal Production and Health Paper No. 172. Rome, Italy: $1-48$. 